\title{
El tejido social y económico de Madrid a través del Anuario Financiero y de Sociedades Anónimas de 1923
}

\author{
José Carlos Rueda laffond*
}

Desde los últimos años de la década de 1910 se regularizó la información recogida en las páginas del Anuario Financiero y de Sociedades Anónimas, publicado en Madrid bajo la dirección de Emilio Ríu, hasta diseñar, ya en los volúmenes iniciales de los años veinte, un perfil teóricamente ajustado de aquellas empresas registradas como Sociedades por acciones. Junto a una relación nominal de las mismas, el Anuario sistematizó además un recuento de algunos Consejos de Administración, y en ocasiones, de sus beneficios cleclarados. Nuestro propósito con la presente comunicación es el de plantear algunas reflexiones provisionales acerca del tejido socio-económico madrileño en la coyuntura especifica de la postguerra europea a partir de la consideración de la Sociedad Anónima como indicador de dinamización y motor de cambio de las estructuras. No se nos escapan tampoco las posibilidades limitaciones 0 deficiencias de este material, así como la necesidad de ser ampliado en lo posible con documentación proveniente del Registro Mercantil.

\footnotetext{
* Universidad Complutense.
} 


\section{HIPÓTESIS DE TRABAJO: SOCIEDADES ANÓNIMAS Y ÉLITES EN $M A D R I D$}

El análisis de los modelos de capitalización de empresas encuentra en la Sociedad por acciones un ejemplo perfilado de cambio cualitativo dado su papel de indicador privilegiado respecto al desarrollo económico y la modernización social ${ }^{1}$. La Sociedad Anónima representa un factor de dinamismo en el proceso de formación, concentración e inversión de capital y en la relación de competencia entre los distintos agentes económicos. Permite también una transformación cuantitativa -ampliación del tamaño medio, de la escala de producción, de la perspectiva para abordar innovaciones... - y una renovada capacidad para abordar estrategias empresariales de mayor alcance ${ }^{2}$.

En líneas generales, hasta el primer decenio del siglo xx, la Sociedad Anónima puede ser considerada un rasgo exótico en el conjunto de las Sociedades españolas. A partir de esta etapa, y respondiendo a la combinación de intereses económicos, especificidades locales y nuevas actitudes sociales, ocupan un segundo lugar, por detrás de las colectivas, en el número total de Sociedades constituidas por formas jurídicas ${ }^{3}$. En el caso catalán, tal y como indica McDonogh, se vincula en buena medida a una trasposición casi automática desde fórmulas tradicionales como la industria casera o los modelos bancarios más o menos rudimentarios. En Madrid, a partir de los primeros años del siglo, se relaciona claramente con la existencia de una élite de perfiles renovados, con un comportamiento económico activo y con orígenes y alcance nacional, élite resultado de una amalgama donde confluyen parte de la antigua nobleza y grupos relativamente homogéneos susceptibles de ser encuadrados bajo el epígrafe de «burgueses» ${ }^{4}$.

1 Para la caracterización sectorial y local de la modernización económica en la España contemporánea, remitimos al conjunto de trabajos recogidos en SÁNCHEZ ALBORNOZ, N. (Comp.) La modernización económica de España, 1830-1930, Madrid, 1985.

2 JimÉnez ARAYA, T. «Formación de capital y fluctuaciones económicas. Materiales para el estudio de un indicador: creación de Sociedades Mercantiles en España entre 1886 y 1970", Hacienda Pública Española, núm. 27 (1974), pág. 137.

${ }^{3}$ Art. cit., pág. 149.

${ }^{4}$ El análisis de élite y de S. A. en Barcelona, en McDonogH, G. W., Las buenas familias de Barcelona. Historia social de poder en la era industrial. Barcelona, 1989, págs. 76 ss. La configuración de una nueva élite de poder a la sombra de la conformación del Sistema de la Restauración, en BAHAMONDE, A. y OTERo, L. E., "Quietud y cambio en el Madrid de la Restauración", en BAHAMONDE, A. Y OTERO L. E. (edits.). La Sociedad madrileña durante la Restauración, 1876-1931, Vol. I. Madrid, 1989, págs. 23 ss. 
En un contexto más global, se ha relacionado el panorama de las Sociedades Anónimas españolas con una tendencia expansiva que arrancando de los años 1914-1918, abarca prácticamente todo el reinado de Alfonso XIII ${ }^{5}$. Si a la altura de 1917 sólo se recogía la existencia de 846 Sociedades por acciones, para 1922 esta cifra alcanzaba un total de $3.506{ }^{6}$. Para el resto del decenio se va a mantener con algunas fluctuaciones esta cantidad, en parte gracias a los dividendos de la coyuntura alcista que rodeó a la Gran Guerra, y como reflejo también del considerable «boom» económico que acompañó a la Dictadura. Por fin, el año 1924 representó el máximo en la constitución de Sociedades, con un capital de más de 2.000 millones de pesetas ${ }^{7}$.

No es gratuita tampoco la elección de 1923 como punto nodal de nuestra investigación. Este año sirve de bisectriz aproximada entre las ambiguas fronteras que separan el desajuste económico en algunos sectores (siderometalurgia, carbón, comercio exterior... ) y la etapa de expansión de la década de los veinte. En un contexto no sólo económico, la etapa 1921-1923 sirve asimismo de bisagra en la crisis terminal del sistema parlamentario y la solución autoritaria en que desembocó la Monarquía.

El concepto de élite corre el peligro de convertirse en una categoría de aplicación prácticamente universal y de significados contradictorios, que, en una limitación incierta sustituya a una terminología desconsiderada por su inaplicabilidad operativa.

La polivalencia de esta expresión puede referirse en tres planos contrapuestos: la visión de la sociedad de la Restauración como una sociedad de élites definida por la defensa de unos valores de prestigio, diferenciación y paternalismo; la importancia cualitativa que adquieren sectores reducidos que, desde un enfoque intelectual, desarrollan teorías de alcance general donde «las minorías conscientes» ocupan un papel

${ }^{5}$ Sobre la realidad económica española en el primer tercio del siglo, TORTELLA, G. «La economía española a finales del siglo XIX y principios del siglo XX», en García DeLGADO, J. L. (edit.). La España de la Restauración. Política, economía, legislación y cultura. Madrid, 1985, págs. 133 y ss; y GortazAR, G., Alfonso XIII, hombre de negocios. Persistencia del Antiguo Régimen, modernización económica y crisis política, 1902-1931. Madrid, 1986, págs. 185 y ss.

${ }^{6}$ Según las estimaciones de los Anuarios Financieros y de Sociedades Anónimas de España de 1918 y 1923.

7 TUNON DE LARA, M., «Progreso técnico y conciencia social, 1898-1936», en GaRCía Delgado, J. L. (edit.). España, 1989-1936: Estructuras y cambio. Madrid, 1984, pág. 58. 
de predestinación; o el análisis de aquellos grupos dirigentes en la esfera política o económica ${ }^{8}$.

Centrándose en este último aspecto, nuestra hipótesis de trabajo considera la existencia en el Madrid del primer tercio del siglo $x \mathrm{x}$ de dos modelos de élite relativamente individualizados. Ambos se entienden como minorías económicas privilegiadas, representativas de una clase, fracción, grupo o sector profesional, caracterizadas por un determinado poder específico de decisión, una actividad de dirección, ciertas competencias y un espíritu reproductivo. Esta función de agrupación coherente se manifiesta, en última instancia, en su importancia como "grupo de variables (...) a las cuales le son inherentes propiedades significativas de subsistema" ${ }^{9}$. Unas se vinculan a un Madrid-capital político y económico, y las otras mantienen un área de actuación e influencia limitada al ámbito local, circunscribiéndose, por tanto, a ramos muy concretos de las economía de Madrid-ciudad, pero capaces en definitiva de articularse en una forma jurídica propia del sistema capitalista desarrollado como es la Sociedad Anónima ${ }^{10}$.

De este modo diferenciamos en el espacio urbano madrileño dos grupos particularizados:

a) Unas élites nacionales homogéneas a pesar de su distinta procedencia geográfica, definidas por el progresivo entroncamiento personal y empresarial. No sólo incluye a aquella «élite de poder» -aristócrata o burguesa - relacionada con la dirección de unos negocios activos, sino también a los responsables directos de unas actividades cada vez más complejas y que paulatinamente engrosan la categoría de "gestores". Junto al interés por inversiones muy localizadas en la ciudad, orientan primordialmente su atención hacia los sectores económicos más pujantes del ámbito nacional: industrias de base o determinados servicios (finan-

${ }^{8}$ El paternalismo de la élite católica catalana ante la cuestión social, en WinSTON, C. M., La clase trabajadora y la derecha en España 1900-1936. Madrid, 1989, págs. 21 y ss. En el caso de Madrid para el XIX, BAHAMONDE, A. Y TORo, J., Burguesía, especulación y cuestión social en el Madrid del siglo XIX. Madrid, 1979. Sobre las élites intelectuales, recordar la idea de Ortega y Gasset a propósito de la Liga de Educación Política: conocimiento profundo de los problemas que obligan a «especializar las cuestiones y a formarnos sobre cada asunto de interés público una opinión sólidamente fundamentada en argumentos técnicos», Ortega y Gasset, J., "Liga de Educación Política» (1913), en Obras Completas, t. X. Madrid, 1988, pág. 247.

${ }^{9}$ APTER, D., Estudio de la modernización, Buenos Aires, 1970, pág. 256.

${ }^{10}$ La dualidad entre Madrid-ciudad, en Bahamonde A. DEL Rey, F. y Martínez Martín J. La Cámara de Comercio e Industria de Madrid. Historia de una institución centenaria, Madrid, 1989; y en Bahamonde, A. y Otero, L. E., Art. cit., págs. 23-25. 
zas, minería, siderometalurgia, transportes, energía eléctrica, compañías de navegación, comercio exterior, etc.).

Nominalmente, esta élite nacional residente en Madrid ha sido perfilada a grandes rasgos, convirtiéndose en punto inexcusable de referencia en cualquier estudio centrado en el escenario madrileño ${ }^{11}$.

b) Combinando una función de dirección y organización con la de ejecución, las élites locales se descubren mucho más heterogéneas, más estrechas, como vanguardias en un panorama donde predomina el pequeño comerciante o el taller con reminiscencias artesanales ${ }^{12}$. Compuesta por una amplia amalgama de empresarios, dos son sus rasgos destacables: el no ligar sus respectivas empresas y el no ligarse con los negocios de la élite nacional, y sospechamos que la no participación en los órganos nacionales de decisión ${ }^{13}$. Sus actividades enlazan estrictamente con la economía local, hacia la producción de bienes de consumo, su comercialización y algunos servicios (harineras y panificadoras, alimentación, bebidas, confección, joyería, pieles y curtidos, carpintería y ebanistería, transportes, artes gráficas, vidrieras y algunas industrias de maquinaria).

Estas élites ignoradas poco tienen que ver con los orígenes o los niveles de renta de la élite económica nacional, con su procedencia social o incluso geográfica, y muchas veces, con sus ocupaciones.

Junto al recurso a una misma forma societaria de actuación, ambas élites conviven en un marco común que superpone una dualidad acentuada entre lo «tradicional» y lo "moderno». En este sentido, cualquier indicador puede señalar el papel de Madrid como ciudad de oficios persistentes o de limitado alcance industrial: el número de contribuyentes por las industrias locales en los años de la Primera Guerra Mundial, la

11 Roldán, S.; García Delgado, J. L. y Muñoz, J., La formación de la sociedad capitalista en España, vol. II, Madrid, 1973, págs. 352 y ss.

${ }^{12}$ Adeleine Daumard ha planteado la misma idea para la burguesía finisecular francesa: "Cette forme du travail bourgeois reposant sur le savoir gérer, le savoir organiser, le savoir diriger s'oppose au savoir exécuter qui caractérisat le travail des milieux populaires et d'une grande partie de la petite bourgeoisie", DAUMARD, A., Les bourgeois et la bourgeoisie en France Paris, 1987, págs. 244.

${ }^{13}$ Respecto a la relación entre la "clase política» y la "clase económica», destacar los trabajos de TUNÓN DE LARA acerca de la constitución de un bloque de poder durante la Restauración: Historia y realidad del Poder. El Poder y las élites en el primer tercio del siglo Xx. Madrid, 1967, y «La burguesía y la formación del bloque oligárquico», en Estudios sobre el XIX español. Madrid, 1972. Desde otra perspectiva, destacar también la revisión del tema en la ponencia presentada a este Simposio por Mercedes Cabrera y Fernando del Rey, "Empresarios y políticos en la crisis de la Restauración». 
muy particular distribución de las clases trabajadoras de la villa y corte según los índices de asociados por oficios en la Casa del Pueblo también para la misma etapa, o los sectores mercantiles predominantes, en especial el número de comerciantes dedicados en un minifundismo agobiante a la venta de subsistencias (Apéndice I) ${ }^{14}$.

Madrid se descubre, asimismo, como capital del Estado de la Restauración, como centro de prestigio o interés para muchas de las decisiones políticas y económicas. Con una atracción operada en un doble sentido, la ciudad es además de un succionador demográfico de primer orden, un núcleo para la recepción y redistribución de capitales, un puesto privilegiado de paso o de asentamiento para toda clase de mercancías, y la plataforma ideal para las críticas de las élites nacional o local respecto a ese mismo Estado ${ }^{15}$. Madrid es, por fin, un núcleo en acelerado proceso de transformación cualitativa, y será en este marco donde se aprecien las contradicciones entre su doble papel de ciudad y de capital, donde se defina la complejidad intrínseca de una jerarquización de tipos sociales difusos 0 de transición, 0 , donde se combinen intereses comunes o tensiones divergentes, fruto ambos de los dispares grados de desarrollo y de las competitividades y alianzas circunstanciales.

\section{EL TEJIDO SOCIAL Y ECONÓMICO MADRILEÑO A TRAVÉS DEL ANUARIO FINANCIERO Y DE SOCIEDADES ANÓNIMAS DE 1923}

\section{Sectores productivos y élites nacionales}

A. El mundo de las finanzas. La evolución en el número de instituciones financieras asentadas o constituidas en la capital representa un primer indicador básico acerca de la tendencia a la modernización en las

14 Según los datos proporcionados por Gloria Nielfa, 4.302 comerciantes constituyen el sector básico de la Alimentación, frente a 4.415 dedicados al resto de sectores. NiELFA, G., Los sectores mercantiles en Madrid en el primer tercio del siglo xx. Madrid, 1985, pág. 112.

15 Recordar por ejemplo, la ofensiva patronal contra el Proyecto sobre Beneficios Extraordinarios generados por la guerra, que encuentra en Madrid, en la Asamblea Magna del Hotel Palace (28 de junio de 1916) su momento álgido. 
APÉNDICE I

A) Cifras de contribuyentes en las industrias madrileñas $(1915,1916$ y 1918)

\begin{tabular}{|c|c|c|c|}
\hline \multirow[b]{2}{*}{ INDUSTRIAS TEXTILES } & 1915 & 1916 & 1918 \\
\hline & & & \\
\hline 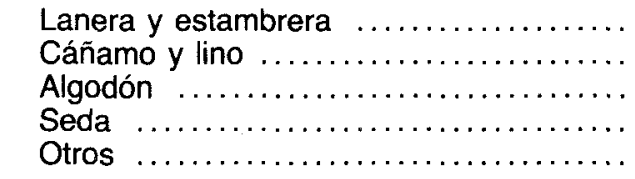 & $\begin{array}{r}2 \\
3 \\
1 \\
2 \\
55\end{array}$ & $\begin{array}{r}3 \\
3 \\
1 \\
1 \\
55\end{array}$ & $\begin{array}{r}7 \\
3 \\
1 \\
1 \\
66\end{array}$ \\
\hline FÁBRICAS TEXTILES & & & \\
\hline $\begin{array}{l}\text { Estampados, tintes y blanqueos } \ldots \ldots \ldots \\
\text { Accesorios de fabricación } \ldots \ldots \ldots \ldots \ldots\end{array}$ & $\begin{array}{l}9 \\
7\end{array}$ & $\begin{array}{l}8 \\
8\end{array}$ & $\begin{array}{l}6 \\
6\end{array}$ \\
\hline INDUSTRIAS METALÚRGICAS & & & \\
\hline $\begin{array}{l}\text { Fundición, refundición, forjado y estirado } \\
\text { Talleres de mecánicos, de carpintería, } \\
\text { ebanistería y aserraderos } \ldots \ldots \ldots \ldots \ldots \ldots \ldots \\
\text { Construcción de máquinas } \ldots \ldots \ldots \ldots \ldots \ldots \\
\text { Construcción de balanzas } \ldots \ldots \ldots \ldots \ldots \ldots\end{array}$ & $\begin{array}{r}219 \\
171 \\
21\end{array}$ & $\begin{array}{r}8 \\
239 \\
169 \\
22\end{array}$ & $\begin{array}{r}344 \\
193 \\
23\end{array}$ \\
\hline INDUSTRIAS QUIMMICAS & & & \\
\hline 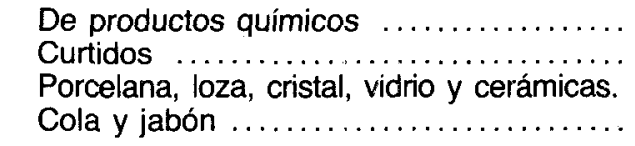 & $\begin{array}{r}148 \\
39 \\
249 \\
119\end{array}$ & $\begin{array}{r}143 \\
38 \\
259 \\
113\end{array}$ & $\begin{array}{r}213 \\
37 \\
401 \\
75\end{array}$ \\
\hline INDUSTRIAS DE ALIMENTOS & & & \\
\hline $\begin{array}{l}\text { Vinos, licores y otras bebidas } \ldots \ldots \ldots \ldots \ldots \\
\text { Bebidas gaseosas } \ldots \ldots \ldots \ldots \ldots \ldots \ldots \ldots \ldots \\
\text { Harinas y sémolas } \ldots \ldots \ldots \ldots \ldots \ldots \ldots \ldots \ldots \\
\text { Chocolates } \ldots \ldots \ldots \ldots \ldots \ldots \ldots \\
\text { Refinación de aceites } \ldots \ldots \ldots \ldots \ldots \ldots \ldots \ldots\end{array}$ & $\begin{array}{r}93 \\
68 \\
484 \\
37 \\
78\end{array}$ & $\begin{array}{r}94 \\
68 \\
501 \\
36 \\
83\end{array}$ & $\begin{array}{r}14 \\
30 \\
381 \\
39 \\
20\end{array}$ \\
\hline INDUSTRIAS VARIAS & & & \\
\hline $\begin{array}{l}\text { Fabricación de papel, de otros productos } \\
\text { similares e industrias derivadas } \ldots \ldots \ldots \ldots \\
\text { Otras fábricas, construcciones y artefac- } \\
\text { tos o máquinas empleados en diferentes } \\
\text { industrias } \ldots \ldots \ldots \ldots \ldots \ldots \ldots \ldots \ldots \ldots \ldots \ldots\end{array}$ & 711 & $\begin{array}{r}38 \\
724\end{array}$ & 1.018 \\
\hline TOTAL GENERAL $\ldots \ldots \ldots \ldots \ldots \ldots \ldots \ldots$ & 2.563 & 2.611 & 2.920 \\
\hline
\end{tabular}

Fuente: Anuarios Estadísticos de España, 1915, págs. 135 ss.; 1916, págs. 126 y ss.; 1918 , págs. 275 y ss.

La distribución de contribuyentes se ha realizado de acuerdo a los apartados ofrecidos por el Anuario. 
B) Comparación entre los contribuyentes de las industrias madrileñas y barcelonesas en 1916 y 1918

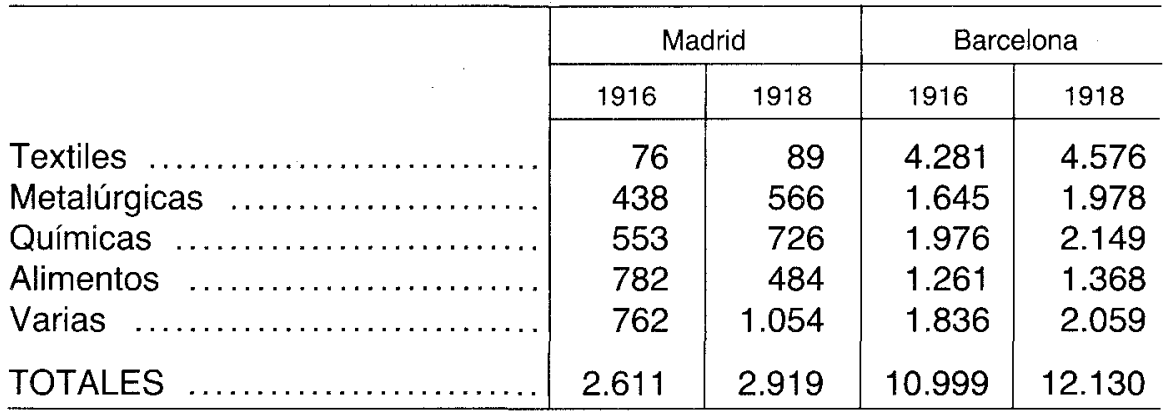

Fuente: Cuadro A.

C) Asociaciones con mayor número de afiliados en la Casa del pueblo de Madrid, 1917

Matarifes y similares ............................... 10.574

Albañiles «El Trabajo» ............................. $\quad 4.605$

Obreros ferroviarios .............................. $\quad 3.397$

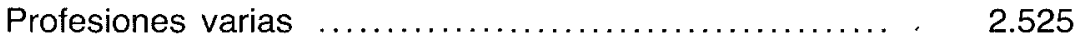

Cocheros de Madrid «La Unión» ...................... $\quad 2.400$

Panaderos candealistas ............................... $\quad 1.900$

Arte de Imprimir ................................... $\quad 1.337$

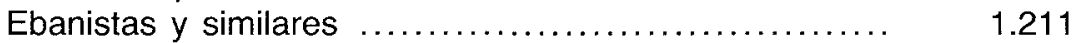

Carpinteros de taller .............................. $\quad 1.200$

Agrupación Socialista ............................... $\quad 1.061$

Agr. Gral. de Dependientes de Comercio ............... $\quad 1.000$

Agr. Gral. de Camareros y similares ................. $\quad 957$

Constructores de Carruajes ........................ $\quad 920$

Constructores de Calzado ........................... $\quad 900$

Fuente: Anuario Estadístico de España, 1917, págs. 491 y ss. 
estructuras económicas madrileñas. Según los datos del Anuario Financiero y de Sociedad Anónimas de 1923, Madrid, es domicilio social para un $15 \%$ de los bancos de todo el país inscritos como Sociedades por acciones, y para un $51,7 \%$ de las Sociedades de Crédito diverso ${ }^{16}$. La etapa coincidente con la conflagración europea a los años inmediatamente posteriores constituyen el telón de fondo para un dilatado crecimiento de sociedades bancarias, y en la mayoría de los casos, también de beneficios declarados: en 1918 se crean el Banco Urquijo y la Banca López Quesada, en 1919 el Central, y al año siguiente el Banco de Crédito Industrial, el Calamarte, el Hispano-Suizo para empresas eléctricas, el Saínz y el Banco Germánico de la América del Sur (Apéndice II).

La banca constituye un primer escenario al que debemos acudir para la cuantificación nominal de la élite económica nacional. Indudablemente, los nombres de Antonio Basagoiti, el marqués de Cortina, el marqués de Urquijo, Luis de Urquijo y Ussía o el marqués de Aldama se entremezclan estos años con unas sociedades que, en esta coyuntura alcista, adquieren sus rasgos tipificadores característicos, modelándose ya como Banca Comercial o de Negocios, y articulándose hacia la participación activa en

APÉNDICE II

Beneficios declarados por la banca madrileña, 1915-1921

\begin{tabular}{|c|c|c|c|c|c|c|c|}
\hline Bancos & 1915 & 1916 & 1917 & 1918 & 1919 & 1920 & 1921 \\
\hline Hispano-Americano & 3,29 & 4,60 & 5,54 & 8,96 & 12,85 & 17,66 & 15 \\
\hline Español de Crédito & 1,40 & 1,40 & 1,41 & 2,14 & 2,73 & 3,52 & 5,10 \\
\hline Castilla........... & 0,57 & 0,47 & 0,56 & 1,37 & 0,86 & 1,08 & 0,42 \\
\hline Central & - & - & - & - & - & 4,61 & 5,90 \\
\hline Urquijo & - & 一 & - & 7,03 & 6,09 & 6,77 & 6,58 \\
\hline López Quesada & - & - & - & 0,11 & 0,83 & 1,39 & 1,51 \\
\hline Hipotecario .... & 2,68 & 2,77 & 3,46 & 5,43 & 4,87 & 3,37 & 3,81 \\
\hline De España & 43,4 & 43,5 & 79,3 & 75,1 & 53,9 & 72,7 & 119,8 \\
\hline
\end{tabular}

Fuente: Elaboración propia a partir de los datos ofrecidos por el Anuario Financiero y de Valores Mobiliarios de 1916 y los Anuarios Financieros y de Sociedades Anónimas de 1918 y 1923.

Nota: Los beneficios en millones de pesetas.

${ }^{16}$ Estimación propia a partir de los Anuarios Financieros y de Sociedades Anónimas de 1918 y 1923. Sobre el desarrollo bancario en Madrid, MUÑOz, J., «La expansión bancaria entre 1919 y 1926: La formación de una banca nacional», Cuadernos de ICE, vol. VI, 1978, especialmente págs. 123 y ss. 
la eclosión de sociedad anónima. Esta presencia manifiesta la imbricación entre las instituciones bancarias y la financiación de determinadas empresas punta, caso de las sociedades petrolíferas, las mineras, las eléctricas, los ferrocarriles, las siderometalúrgicas o la intervención en otras sociedades bancarias, adoptando formas que oscilan o combinan «los servicios financieros prestados» o la simple presencia de representantes en los consejos de administración de tales sociedades anónimas ${ }^{17}$.

En este sentido, hablar de élite nacional externa a la economía local, o al menos no exclusivamente circunscrita a ella, debe tener en cuenta la procedencia geográfica de los prohombres del mundo financiero, las preferencias geográficas y el encuadramiento, -aunque sólo sea como indicio-, en los diversos consejos de administración ${ }^{18}$.

B. Mineria, metalurgia y ferrocarriles. Estos tres sectores ofrecen el porcentaje más alto de sociedades que, domiciliadas en la capital, orientan sus inversiones extramuros a la ciudad. En el caso de las mineras esta diferenciación resulta abrumadora: sólo una de las 37 sociedades reflejadas en el Anuario de 1923 se dedica a la explotación de un pozo localizado en los límites de la provincia ${ }^{19}$. El resto de las sociedades anónimas, caracterizadas por su dinaminazión y la práctica de formas de entroncamiento o integración, se reparte por toda la Península.

La vinculación entre la élite nacional y las tres sociedades metalúrgicas asentadas en Madrid en 1923 es, asimismo, nítida: la Sociedad Metalúrgica Duro-Fleguera (1900), presidida por el marqués de Urquijo, la Sociedad Minero-Metalúrgica de Ponferrada (1918), presidida por José Luis Ussía Cubas, y la Sociedad Electro Metalúrgica Ibérica (1918), encabezada por el duque de Tetuán ${ }^{20}$.

Idéntico comportamiento aparece en el conjunto de compañías de ferrocarril. Caso ejemplificador es el del consejo de administración de la

17 Por ejemplo, el servicio financiero que realizan los bancos del grupo Urquijo a la Compañía del Ferrocarril de Madrid a Aragón en el año 1923. Anuario Financiero..., Il parte, pág. 773 .

${ }_{18}$ Tomemos el caso de Estanislao Urquijo y Ussía, miembro, en 1923, de los consejos de administración de un total de 24 empresas, o de Antonio Basagoiti, miembro de 11.

${ }^{19}$ Se trata de la sociedad "Los Amigos", que en 1918 se dedica a la explotación de un pozo asentado en Cenicientos. Anuario Financiero..., de 1918, pág. 510.

${ }^{20}$ Además, entre otros, la Sociedad Metalúrgica Duro-Felguera cuenta en sus consejos de administración de estos años con González Besada, el marqués de Fontalba, Félix Lazcano, el marqués de Aledo, el marqués de Amurrio o Valentín Ruiz Senén. Anuario Financiero..., de 1918, pág. 430; Anuario Financiero..., de 1923, pág. 657. 
Compañía de Explotación de los Ferrocarriles de Madrid a Cáceres y del Oeste de España (1894), compuesto, entre otros, por Javier Gil Becerril, el marqués de Comillas, el marqués de Aldama o Luis Urquijo ${ }^{21}$. El volumen de capital de esta sociedad (nominal: 37 millones; desembolsado: 25), sirve de perfecto indicador del respaldo financiero imprescindible, tal y como se ha señalado repetidamente, que existe tras las compañías de ferrocarril. Hay que destacar también la importancia colateral de un Madrid que es mercado de intercambio y de consumo, y en definitiva, centro privilegiado gracias al diseño de la red ${ }^{22}$.

C. Otros sectores. Multitud de ejemplos reafirman lo considerado en párrafos anteriores. Otros sectores repiten la vinculación y dependencia con lo que hemos denominado élites nacionales; tal es el caso de las dedicadas al comercio exterior, como la Sociedad Española de Comercio Exterior relacionada con el Grupo Urquijo, las sociedades navieras, que, en el caso de la única domiciliada en Madrid (la Sociedad Española de Construcción Naval, 1908), con un capital nominal de 81 millones y uno desembolsado de 59) vuelve a reiterar nombres tan significativos como Tomás de Zubiria, Javier Gil Becerril, el marqués de Urquijo o el conde de Gamazo; o la Sociedad General Azucarera de España (1903), cuyo consejo lo integran Antonio Basagoiti, Joaquín Sánchez de Toca, Basilio Paraiso, el ya citado Gil Becerril y otros; y, por fin, la Unión Azucarera Española (1905), que con un capital de 15 millones de pesetas, recoge los nombres del marqués de Cortina, Tirso Rodrigañez, Julio Otero, Antonio García Gil o Tomás Castellano, los cuatro últimos también presentes en la General Azucarera ${ }^{23}$.

${ }^{21}$ El consejo de la Compañia de Explotación de los FF de Madrid a Cáceres y Portugal, y del Oeste de España está compuesto en 1923 por el marqués de Comillas, Javier Gil Becerril, el marqués de Aldama, Luis de Urquijo, el conde de Gamazo, el barón de Satrústegui, José Gil de Biedma y Alfredo Loewy. Anuario Financiero..,, de 1923, II parte, pág. 767.

${ }^{22}$ Gomez MendozA, A., "Ferrocarril, abastecimientos y mercado nacional», en BAHAMONDE, A., y Otero, L. E., (edits.) La sociedad madrileña de la Restauración, t. I, 18761931, págs. 352-355.

23 Para la Sociedad Española de Comercio Exterior, Anuario Financiero, de 1923, II parte, pág. 413; la Sociedad Española de Construcción Naval, Ibidem, I parte, pág. 614; la Sociedad General Azucarera de España, Ibidem, I parte, pág. 481; la Unión Alcoholera Española, Ibidem, I parte, pág. 433. 
2. La economía local: entre la modernización y la pervivencia

Élites nacionales y economía local

Estos son los años también de expansión en el número de Sociedades por acciones de estricto alcance local, circunscritas a ramos capitalinos muy dinámicos, y al tiempo, interrelacionados por las élites nacionales. Reflejo del crecimiento demográfico, de la progresiva modernización de las estructuras y de la necesidad de adecuar un conjunto de servicios a nuevas necesidades, cabe citar la importancia en el volumen de capital, en los beneficios o en la composición nominal de los Consejos de Administración de sectores como los tranvías, el metropolitano, las sociedades inmobiliarias, las eléctricas o el subsector químico-farmacéutico.

El rasgo más relevante en los tranvías madrileños es la ratificación del proceso de concentración de las cinco líneas principales que operan en la ciudad. Hasta 1920 el grueso de las acciones de estas cinco Compañías (Tranvias del Este de Madrid, Tranvías de Estaciones y Mercados, General Española de Tranvías, Madrileña de Tracción y Tranvía del Norte de Madrid) estaba controlada por la sociedad General de Tranvías Eléctricos de España, vinculado a capital belga ${ }^{24}$. En relación con el proceso de configuración de un «capitalismo nacional», en diciembre de 1920 se constiiuye la Sociedad Madrileña de Tranvías, con un capital español de 70 millones de pesetas. La Sociedad Madrileña... adquirirá entonces prácticamente el cien por cien de las acciones de la General de Tranvías Eléctricos ${ }^{25}$. De nuevo encontramos en su Consejo a parte representativa

${ }^{24}$ El Consejo de Administración de la Sociedad General de Tranvías Eléctricos de España está compuesto en 1918 por G. de Bauer, Z. Glorieux, B. de Joughe, A. de Hault y J. Wilmart por la parte belga. Otros consejeros son L. Cocagne, J. Navarro Reverter, C. Caamaño, L. García de Rivera, C. Aguado y S. Inneraty; Anuario financiero..., 1923, II parte, pág. 862.

${ }^{25}$ Adquisición de valores de las cinco compañias madrileñas de tranvías por parte de la sociedad generai de tranvias eléctricos de España

Empresas $\quad$ Importes de los valores

ACCIONES

Tranvía del Este

Tranvía de Estaciones y Mercados ..............

General Española de Tranvías
18.000 .000 de pts.

2.000 .000 de pts. 417.000 de pts. 
de las élites económicas nacionales: Valentín Ruiz Senén como Presidente, y Juan Urrutia, el duque de Seo de Urgel o Julián Navarro Reverter entre los vocales ${ }^{26}$.

Las relaciones entre las Compañías de Transporte y las sociedades Inmobiliarias aparecen en dos ejemplos paradigmáticos y de distinta fortuna en Madrid. La vinculación entre la Compañía Madrileña de Urbanización de tranvías y su homónima de edificación. Bajo la presidencia de José Canuedo y la dirección de Arturo Soria, ambas entran en quiebra en 1917 y 1914 respectivamente ${ }^{27}$. O la relación entre la Compañía Metropolitano Alfonso XIII (1919), y la Sociedad Urbanizadora Metropolitana, (1918) y Edificadora Metropolitana (1918), en cuyos consejos figuran los nombres de Miguel y José María Otamendi, Carlos de Eizaguirre, González Echarte, Carlos Mendoza, Venancio Echevarría e, indirectamente, con el apoyo financiero del monarca, el duque de Miranda ${ }^{28}$. También entroncada al grupo permanece la Compañía Anónima de Electricidad Mengemor (1904), dedicada al alumbrado del barrio de Tetuán.

Asimismo, el sector eléctrico sufre en los años paralelos a la Primera Guerra Mundial una dinámica de nacionalización, sustituyendo la intervención foránea por capitales españoles, consagrando también una tendencia a la concentración y las prácticas casi monopolísticas ${ }^{29}$. Cuatro grandes Sociedades acaparan el mercado madrileño: la Cooperativa Electra Madrid (1910), y la S. A. Hidroeléctrica Española (1907), que prácticamente comparten los consejos de Administración: Basagoiti, F. M.

Madrileña de Tracción

5.960 .000 de pts.

Tranvía del Norte de Madrid Arriendo

Fuente: Anuario Financiero... de 1923, II parte, pág. 862.

${ }^{26}$ Componen el Consejo de Administración de la Sociedad Madrileña de Tranvías Eléctricos de España, J. Navarro Reverter, C. Caamaño, S. Inneraty, C. Aguado, el barón de Empay, Henry Urban, G. Ithier, E. Le Roy, P. Delannoy, J. Kessels, L. Sánchez-Cuervo, el duque de Seo de Urgel, José de Taramona, el marqués de San Damián, C. Figueroa, J. Urrutia y V. Ruiz Senén. Anuario Financiero..., de 1923, II parte, págs. 863-865.

${ }^{27}$ Anuario Financiero... de 1918, pág. 374; Anuario Financiero..., de 1923, II parte, pág. 614.

${ }^{28}$ La participación de Alfonso XIII en la Compañía Metropolitano, en GorTaZAR, G., Op. cit., págs. 124 ss.

${ }_{29}$ Sobre el panorama de las eléctricas en el Madrid del primer decenio del siglo, Simo Ruescas, J., "La Cooperativa Electra Madrid y los inicios del monopolio compartido en la industria eléctrica madrileña, 1905-1912", en BAHAMONDE, A. y OTERO, L. E. (edits.), Op. cit., I, págs. 419-427. 
Ibarra, González Heredia, Urritia, el marqués de Aldama, etc.; Unión Eléctrica Madrileña (1912), que, junto a Eléctrica de Castilla y la Sociedad de Electrificación Industrial dependen del grupo Urquijo; y la sociedad Hidráulica Santillana (1905), que cuenta con un consejo plenamente "nobiliario»: el marqués de Santillana, el de Larios, el de Torrecilla, el de Villamejor, el de Torrelaguna, el de Monteagudo, el de Cortina, el barón de Satrústegui y Antonio Maura ${ }^{30}$. Del mismo modo, la élite nacional también está presente en la única sociedad anónima de gas de toda la ciudad: Gas Madrid, S.A. (1921) ${ }^{31}$.

Otro de los subsectores que más se destacan numéricamente es el de Materiales Eléctricos. De las 104 Sociedades por acciones existentes en España en 1923, 30 se encuentran asentadas en Madrid. Entre ellas destacan AEG Ibérica de Electricidad (1909), con un capital de cinco millones de pesetas, y un consejo entre cuyos miembros resalta Mariano Matesanz, de la Cámara de Industria; y la Sociedad Española del Acumulador Tudor (1897), que, con un capital casi cuatro millones, vuelve a reunir en su consejo a firguras como Urrutia, Federico Echevarría o Valentín Ruiz Senén ${ }^{32}$.

Para concluir este apartado, citar a la gran empresa madrileña dedicada a la elaboración de productos químicos. Contradictoriamente, en un momento de nacionalización económica, la Unión Española de Fábricas de abonos, productos químicos y superfosfatos, (1910), depende de capital francés, contando con un Consejo de Administración totalmente extranjero ${ }^{33}$.

Las élites económicas locales

Madrid no es sólo sede social para un conjunto de empresas imbricadas entre sí por medio de una élite de alcance nacional. Podemos considerar que entre estos grupos y el Madrid de las persistencias co-

${ }^{30}$ Anuario Financiero..., de 1923, I parte, págs. 714-719.

${ }^{3}$ En su Consejo de administración destacan, entre otros, J. Urrutia, V. Ruiz Senén, F. Setuaín, S. Inneraty. Anuario Financiero..., de 1923, I parte, pág. 479.

${ }_{32}$ Anuario Financiero..., de 1923, II parte, págs. 378 y 379 respectivamente.

${ }_{3} 3$ Su Consejo está formado por $H$. de Peyerimholt, T. Ausbacher, L. Jenouvrier, L. de Maniquet, M. Kapferer, el Vizconde de Montereux y T. Chapuis. La fábricas de la empresa se encuentran en Alicante, Málaga, Sevilla y Valencia. Anuario Financiero..., de 1923, II parte, pág. 122. 
merciales o artesanas, incluso protoindustriales, la ciudad es también escenario para la aparición y aparente consolidación de un tipo muy particular y heterogéneo de empresas. Son aquellas que adoptan la forma jurídica de Sociedad Anónima, propia, ya lo hemos apuntado, de la maduración de patrones capitalistas, y al mismo tiempo, aquellas que no superan las 750.000 o el millón de pesetas de capital.

Junto a la orientación hacia actividades muy definidas, estas Sociedades incluso unen en el proceso productivo la producción y distribución de los bienes económicos. Tampoco desarrollarán una tendencia a la integración o repetición nominal entre los diversos Consejos de Administración.

Pero es indudable su importancia como minoría dirigente en los reducidos límites de la economía urbana, especialmente en sus esfuerzos por individualizarse frente a esa otra economía local de oficios (Apéndice III). Su evolución en el tiempo está por saber, auqnue pasa ineludiblemente por un estudio particularizado de cada caso. Así, mientras Almacenes Rodríguez (inscrita como Sociedad Anónima en 1920), los MadridParís (1920), o la Sociedad Española de Grandes Almacenes Victoria (1920), son los avanzados en un tipo de estructura mercantil precapitalista sólida, las pequeñas fábricas eléctricas de barriadas - Cooperativa Eléctrica de los Carabanchel, la Eléctrica de las Carabancheles, la Sociedad de Electricidad del Barrio de Nueva Numancia o la Sociedad de Electricidad del Mediodía-, quedan prácticamente anuladas o subsumidas ante la monopolización del sector. Del mismo modo, otras Sociedades por acciones, caso de la S.A. del Omnibús de Madrid (1918) no representa a la altura de 1923 sino una sombra ante las Sociedades de Tranvías o el Metropolitano.

Queda asimismo por efectuar un estudio acerca de la relación de este empresario local con respecto a las diversas organizaciones patronales. El análisis de su previsible presencia en asociaciones como "La Única" o la Federación Gremial Española planteará entonces una perspectiva más amplia acerca de las estrategias y las actitudes particulares de estos grupos. 
APÉNDICE III

Élites locales y sociedades anónimas. Ejemplos representativos

\begin{tabular}{|c|c|c|}
\hline NOMBRE & SOCIEDAD & SECTOR \\
\hline ÁLVAREZ RODENAS, M. & Biblioteca Hispania & Artes Gráficas \\
\hline ARROYO, Ramón & La Cuchillera Mecánica & $\begin{array}{l}\text { Maquinaria y Construc- } \\
\text { ciones Mecánicas }\end{array}$ \\
\hline BARTRINA, Camilo & $\begin{array}{l}\text { C. }{ }^{a} \text { General de Coches de } \\
\text { Lujo }\end{array}$ & Transportes \\
\hline CARRO, Rafael & El Gremio de Pescados & Alimentación \\
\hline CASADO, Mariano & La Fortuna & Alimentación \\
\hline CLOT, J. J. & $\begin{array}{l}\text { La Victoria. Sociedad } \\
\text { Fabril de Productos } \\
\text { Alimenticios y Destilería } \\
\text { Franco-Española }\end{array}$ & Alimentación \\
\hline CORT, César & La Textil Castellana & Textil \\
\hline DELGADO BARRETO, M. & $\begin{array}{l}\text { General Española de } \\
\text { Transportes Aéreos }\end{array}$ & Transportes \\
\hline ESPINOS, Miguel & $\begin{array}{l}\text { C. }{ }^{a} \text { Madrileña de Panifica- } \\
\text { ción }\end{array}$ & Harineras y Panificac. \\
\hline $\begin{array}{l}\text { GANCEDO RODRÍGUEZ, } \\
\text { G. }\end{array}$ & Almacenes Rodríguez & Confecciones \\
\hline GÓMEZ VALLEJO, A. & El Laurel de Baco & Bebidas \\
\hline GÓMEZ, Ramón & S. A. del Carruaje & Diversas \\
\hline GONZÁLEZ, Victoriano & $\begin{array}{l}\text { Unión Industrial de } \\
\text { Maestros Vidrieros y } \\
\text { Hojalateros }\end{array}$ & Vidrieras \\
\hline GONZÁLEZ CONDE, D. & $\begin{array}{l}\text { S. A. Pesquera «La Fami- } \\
\text { liar» }\end{array}$ & Alimentación \\
\hline GUILLEN SAENZ, J. & Almacenes Victoria & Comercio \\
\hline HERRERO, Manuel & Manuel Herrero, S. A. & Transportes \\
\hline JOVE, Marcelo & Neumático Michelín & Automóviles \\
\hline DE LOMA, Álvaro & $\begin{array}{l}\text { Española de Automóviles } \\
\text { Renault }\end{array}$ & Automóviles \\
\hline LOMABELLA, Felipe & $\begin{array}{l}\text { C. }{ }^{a} \text { Española del Tráfico } \\
\text { Aéreo }\end{array}$ & Transportes \\
\hline LLOPIS, A. & $\begin{array}{l}\text { Productos Farmacéuticos A } \\
\text { Llopis, S. A. }\end{array}$ & Químico \\
\hline $\begin{array}{l}\text { MARTÍNEZ Y MARTÍNEZ, } \\
\text { J. }\end{array}$ & $\begin{array}{l}\text { S. A. del Omnibús de } \\
\text { Madrid }\end{array}$ & Transportes \\
\hline MENERO, Ramón & La Progresiva & Confecciones \\
\hline DE NERO, Pedro & La Veloz & Transportes \\
\hline PAULS, José & Madrid Industrial & Confecciones \\
\hline PEREZ PRIETO & El Laurel de Baco & Bebidas \\
\hline PINEDA, Enrique & Sucesores de Matías López & Alimentación \\
\hline
\end{tabular}


El tejido social y económico de Madrid a través del Anuario ...

\begin{tabular}{|c|c|c|}
\hline NOMBRE & SOCIEDAD & SECTOR \\
\hline PULIDO, Angel & $\begin{array}{l}\text { Sociedad Editorial de } \\
\text { España }\end{array}$ & Artes Gráficas \\
\hline DE RAMOS, José & La Alfilerería Central & Metalurgia \\
\hline SACRISTAN, Antonio & $\begin{array}{l}\text { Sociedad Editorial de } \\
\text { España }\end{array}$ & Artes Gráficas \\
\hline SÁNCHEZ DOMÍNGUEZ, & J.Eléctrica del Mediodía & Eléctricas \\
\hline SÁNCHEZ, Alejandro & $\begin{array}{l}\text { Cooperativa Eléctrica de } \\
\text { los Carabancheles }\end{array}$ & Eléctricas \\
\hline SAN MARTÍN, Luis & Continental Exprés & Transportes \\
\hline SANTOS, Carlos & La Fortuna & Alimentación \\
\hline SEGURA, José & El Triunfo & Alimentación \\
\hline SUAREZ PAREDES, M. & $\begin{array}{l}\text { La Fama Industrial } \\
\text { Harino-Panadera }\end{array}$ & Harineras \\
\hline SUAREZ, Rafael & El Financiero & Artes Gráficas \\
\hline TORRE ISUNZA, P. & $\begin{array}{l}\text { Fábrica de ladrillos de } \\
\text { Valderribas }\end{array}$ & $\begin{array}{l}\text { Cemento, Cerámica } \\
\text { y Ladrillo }\end{array}$ \\
\hline TORROJA, José María & Estereográfica Española & Artes Gráficas \\
\hline DEL VAL, Ciriaco & La Fortuna & Alimentación \\
\hline VELAZQUEZ, Gerardo & Royal y Compañía & $\begin{array}{l}\text { Joyeros, Plateros y Re- } \\
\text { lojeros }\end{array}$ \\
\hline VILLACIEROS, Anselmo & Al Capricho & Confecciones \\
\hline
\end{tabular}

Fuente: Elaboración propia a partir del Anuario Financiero y de Sociedades Anónimas de 1923.

Hemos distribuido en varios ramos significativos el conjunto de sociedades anónimas susceptibles de servir como indicadores de las élites locales madrileñas:

Harineras y panificadoras $(\mathrm{F}$ y $\mathrm{C}) \ldots \ldots \ldots \ldots \ldots$

PP alimenticios y bebidas ( $F$ y $C) \ldots \ldots \ldots \ldots \ldots$

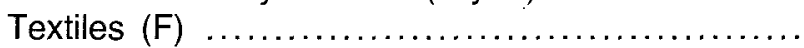

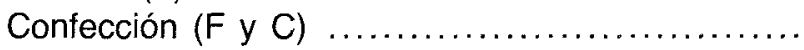

Pieles y curtidos $(F$ y $C) \ldots \ldots \ldots \ldots \ldots \ldots \ldots \ldots$

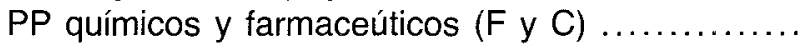

Muebles, carpintería y tapiceria $(F) \ldots \ldots \ldots \ldots \ldots$

Joyerías, platerías y relojerías $(F$ y $C) \ldots \ldots \ldots \ldots$

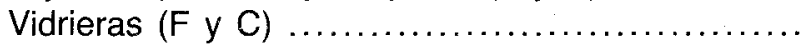

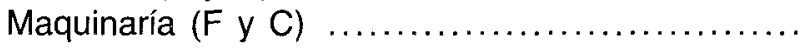

Artes gráficas

$11 \quad(52)$

$14 \quad(77)$

$5(118)$

$7 \quad(28)$

$1 \quad(40)$

$27(166)$

$4 \quad(8)$

7 (16)

$4 \quad(21)$

$47(244)$

$21(103)$ 
Reparación y venta de piezas de automóvil .......

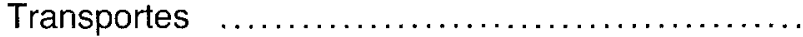

Diversas

Fuente: Anuario Estadístico y de Sociedades Anónimas, Madrid 1923. $F=$ Fabricación; $\mathrm{C}=$ Comercialización; Cifras en paréntesis $=$ total nacional.

Los subsectores antes citados constituyen en el número de sociedades anónimas existentes en España un 31,8\%. El total de sociedades domiciliadas en Madrid dedicadas a estos negocios suponen un $35 \%$ de las sociedades anónimas inscritas en la capital. Harineras y panificadoras, alimentación, confección, pieles y curtidos, muebles, joyeros,... vidrieros y transportes cuentan mayoritariamente con sociedades anónimas con un capital nominal igual o inferior al millón de pesetas. Sólo textiles y artes gráficas superan como media dicha cifra.

Podemos considerar como muy reducida la incidencia que, respecto al conjunto nacional y al total de domiciliadas en Madrid, tienen las sociedades anónimas dedicadas a los subsectores referidos. Estos no forman parte tampoco de aquellos especialmente beneficiados por la coyuntura bélica. Domicilio social y marco geográfico de actuación tienden también a confluir e identificarse.

Algunas de estas sociedades se configuran con un capital nominal bajisimo. Esto, junto a la presencia frecuente de los mismos apellidos en varios consejos de administración, apunta la hipótesis de encontrarnos ante sociedades mayoritariamente de transición entre formas jurídicas «tradicionales» y las sociedades anónimas con capital o consejo de administración verdaderamente representativo.

Presentan también rasgos heterogéneos dentro de cada subsector. Así por ejemplo, artes gráficas reúne bibliotecas, agencias de noticias, sociedades fotográficas, talleres tipográficos, sociedades de prensa y sociedades editoriales, junto a periodistas de alcance nacional como Torcuatro Luca de Tena, Rafael Gasset o Nicolás Urgoiti ${ }^{34}$. El subsector de productos alimenticios posee un capital medio de 634.000 pesetas, mientras que una de las sociedades que lo componen (Los Sucesores de

${ }^{34}$ Entre las sociedades de artes gráficas destacan: Biblioteca Hispania (1915), Fabrá (1919), Sociedad Anónima Estereográfica Española (1916), KODAK, S.A. (1913), Prensa Española (1909), El Imparcial (1916), Editorial Reus (1919), o Calpe (1918). Anuario Financiero..., de 1923, I parte, págs. 448-456. 
Matias López, S.A. (1914) cuenta con un capital de dos millones ${ }^{35}$. Idénticas características denota el subsector de confección: junto a los ya destacados Almacenes Rodríguez, S.A., con un capital de diez millones, conviven siete pequeñas sociedades con un capital medio de 522.500 pesetas en $1923^{36}$.

Otros subsectores manifiestan, en cambio, evidentes homogeneidades: textiles posee un capital medio para 1923 de cinco millones. Esta cifra se debe a la presencia de dos empresas que superan con creces los níveles de capital que en este capítulo incluimos. La Industria Textil Alicantina (1921), con un capital nominal de siete millones, y fundamentalmente, Industrias del Yute, S.A. (1920), presidida por el conde de Mortones y con un capital nominal de 17 millones, y establecimientos fabriles en Hospitalet, Vizcaya, Vinalesa y Sumilla. En otros esta homogeneidad es a la caja. Tal es el caso de joyerías, platerías y relojerías, con un capital medio de 440.000 pesetas, y donde sólo destaca una sociedad con un millón de capital Argentum, S.A., (1917) ${ }^{37}$.

Reseñar también la existencia de concesionarios o filiales de empresas extranjeras que por el volumen de capital o por sus consejos de administración en España no corresponden a los modelos prototípicos de sociedades relacionadas con la élite económica nacional. Como ejemplo característico, Neumático Michelín (1908), con un capital para 1923 de 300.000 pesetas. Su director es Marcelo Jove ${ }^{38}$.

Otras sociedades, por fin, complementan otros subsectores integrados en los intereses de la élite nacional. Así, la Sociedad General de Autobús de Madrid (1922), o la ya citada Sociedad Anónima del Omnibús de Madrid constituyen dos pequeñas empresas -el capital nominal de la última es de 750.000 pesetas-, muy alejadas de los 18 millones de capital nominal de la Sociedad del Tranvía del Este de Madrid, o los 34 de la Compañía Metropolitano Alfonso XIII ${ }^{39}$.

De las 220 sociedades que integran los ramos antes citados puede extraerse una relación nominal más o menos detallada de las que hemos denominado élites económicas locales. Indudablemente, cualquier conclu-

${ }^{35}$ Anuario Financiero..., de 1923, II parte, págs. 84 y ss.

36 $\mathrm{Ibidem}$, Il parte, págs. 692-694.

${ }^{37}$ Ibidem, II parte, págs. 27,28 y 431 , respectivamente.

${ }^{38} \mathrm{Ibidem}$, I parte, págs. 480-484.

${ }^{39}$ Veintitres son las sociedades anónimas dedicadas al ramo de transporte domiciliadas en Madrid en 1923. Su capital medio es de 1,19 millones de pesetas. Las sociedades de transporte, en el Anuario Financiero..., de 1923, II parte, págs. 52-57. 
sión sobre las mismas debe señalar la enorme complejidad que supone intentar encuadrarlas en unas líneas donde, conservando su diversidad interna, queden claras la coherencia y uniformidad de esteos grupos. Esta diversidad se traduce en la relativa jerarquización que actividades, competencia, poder específico o prestigio debe deparar. La coherencia pasa ineludiblemente por su papel activo en el escenario económico madrileño, y en la articulación de tal comportamiento por medio de las sociedades por acciones. Esta constatación permite ampliar nuestras perspectivas acerca de las élites y del conjunto de la sociedad madrileña - y nacional, en cuanto que Madrid es, en buena medida, reflejo del todo nacional- durante la crisis de la Restauración. 